\title{
serie Non-price competition, real rigidities and inflation dynamics
}

Francesco Turino

Ivie 
Los documentos de trabajo del Ivie ofrecen un avance de los resultados de las investigaciones económicas en curso, con objeto de generar un proceso de discusión previo a su remisión a las revistas científicas. Al publicar este documento de trabajo, el Ivie no asume responsabilidad sobre su contenido.

Ivie working papers offer in advance the results of economic research under way in order to encourage a discussion process before sending them to scientific journals for their final publication. Ivie's decision to publish this working paper does not imply any responsibility for its content.

La Serie AD es continuadora de la labor iniciada por el Departamento de Fundamentos de Análisis Económico de la Universidad de Alicante en su colección "A DISCUSIÓN" y difunde trabajos de marcado contenido teórico. Esta serie es coordinada por Carmen Herrero.

The AD series, coordinated by Carmen Herrero, is a continuation of the work initiated by the Department of Economic Analysis of the Universidad de Alicante in its collection "A DISCUSIÓN", providing and distributing papers marked by their theoretical content.

Todos los documentos de trabajo están disponibles de forma gratuita en la web del Ivie http:/ / www.ivie.es, así como las instrucciones para los autores que desean publicar en nuestras series.

Working papers can be downloaded free of charge from the Ivie website http://www.ivie.es, as well as the instructions for authors who are interested in publishing in our series.

Edita / Published by: Instituto Valenciano de Investigaciones Económicas, S.A.

Depósito Legal / Legal Deposit no.: V-2498-2009

Impreso en España (junio 2009) / Printed in Spain (June 2009) 
WP-AD 2009-17

\title{
Non-price competition, real rigidities and inflation dynamics
}

\author{
Francesco Turino*
}

\begin{abstract}
In the last decade, the analytical progress achieved in the New Keynesian literature has been remarkable. Many of the early assumptions have been relaxed, leading to medium-scale macroeconomic models that are now able to capture many features of real-world data. Nevertheless, modern-day New Keynesian models still assume, as did their early counterparts, that firms compete in the market with no tools other than their relative prices. In particular, this literature has so far neglected the consequences of extending competition between firms to the non-price dimension. This paper tries to fill this gap by enriching the canonical New Keynesian framework to include both price and non-price competition. This has important consequences for the analysis of inflation dynamics, modifying in particular the inflation-marginal cost relationship. As a general result, we show that any activity by firms that boosts demand for their products, without directly affecting their prices, dampens the overall degree of real rigidities in price-setting.
\end{abstract}

Keywords: Non-price competition, inflation dynamics, real rigidity

JEL Classification: E31, L11

\footnotetext{
* This paper was part of my Ph.D. thesis at Universitat Pompeu Fabra. I am grateful to my advisor Jordi Galí for his guidance during this period. Also, I would like to thank the helpful comments of Maria Bigoni, José Dorich, Antonio Minniti and Renzo Orsi. Financial support from Associazione Prometeia in Bologna is gratefully acknowledged.

${ }^{* *}$ F. Turino: University of Alicante. E-mail: fturino@merlin.fae.ua.es
} 


\section{Introduction}

In the last decade, the analytical progress achieved in the New Keynesian literature has been remarkable. Many of the early assumptions have been relaxed, leading to medium-scale macroeconomic models that are now able to capture several features of real-world data. As such, the New Keynesian framework has became a workhorse for the analysis of monetary policy in both academic and central-banking circles.

Nevertheless, modern-day New Keynesian models still assume, as did their early counterparts, that firms compete in the market with no tools other than their relative prices. This literature particularly lacks a formal study that explicitly evaluates the consequences of extending competition between firms to the non-price dimension. In fact, in general equilibrium models with nominal rigidities, the firms' behavior is typically modeled by abstracting from any decisions concerning expenditures for non-price tools, such as investment in quality, advertising and customers' services. This paper tries to fill this gap by extending the canonical New Keynesian framework to an environment where firms face, at the same time, both price and non-price competition.

In this paper, non-price competition refers to any activity by firms that shifts the demand for producers, both their own and those of their rivals, without directly affecting their prices. Several aspects make this dimension of the firms' competition a theoretically interesting feature in models with nominal rigidities. First, assuming, as in the New Keynesian literature, that firms compete for the market only through their relative prices is a simplification that is not always realistic. This is particularly true in oligopolistic or monopolistically competitive industries in which non-price tools often drive the major source of inter-firm rivalry. Furthermore, real-world data suggest that firms in fact devote large amounts of resources to these activities. In the US economy, for example, aggregate expenditures on advertising and research and development (R\&D) in the second half of the last century have accounted, on average, for almost $5 \%$ of GDP. ${ }^{1}$ Similar magnitudes characterize advertising and R\&D markets in other industrialized countries. ${ }^{2}$

Second, although we have identified non-price tools as demand shifters that do not directly modify output prices, non-price competition among firms may still have indirect effects on their pricing behavior. As emphasized in the industrial organization literature, a typical feature of nonprice tools is that they may modify the degree of substitutability among goods. ${ }^{3}$ For instance, by spending on advertising, a firm may successfully persuade customers about peculiar characteristics of its product, or by investing in quality (product innovation), it may increase the degree of differentiation between its product and those of its rivals. Through these activities, therefore, firms may successfully build customers' loyalty for their products, thereby gaining monopolistic and pricing power. This feature is particularly interesting in light of the New Keynesian theory. This literature has in fact emphasized firms' pricing behavior as a key determinant for both inflation dynamics and the persistence of the real effects of monetary policy shocks. From this perspective, therefore, by interacting with the firms' pricing behavior, non-price competition may also affect inflation dynamics. The current New Keynesian literature overlooks this interesting linkage precisely because it assumes that firms compete for the market with no tools other than their relative prices. Therefore, the analysis provided in this paper will focus in particular on understanding

\footnotetext{
${ }^{1}$ This statistic refers to data taken from 1950 to 2003 . Data for R\&D and advertising expenditures are respectively taken from the National Science Foundation (www.nsf.org) and the Newspaper Association of America (http://www.naa.org). Figures for GDP are taken from Federal Reserve Bank of St. Louis (http://research.stlouisfed.org/fred2/).

${ }^{2}$ See Molinari and Turino (2007) for an international comparison.

${ }^{3}$ In fact, in this literature, non-price competition tools, such as advertising and R\&D for product innovation, are often modeled as affecting the degree of substitutability among goods. See, for instance, Lambertini and Mantovani (2008) and the references they provide.
} 
whether and how non-price competition among firms can affect inflation dynamics.

To address this issue, we develop a variant of the Calvo model (1983) by extending the canonical framework to an environment where firms also engage in non-price competition. Building on Spence (1977), this feature is introduced in the model by assuming that consumers' tastes are endogenously determined, depending on the distribution of non-price activities across all the firms. To emphasize that our results depend only on the interaction between non-price policy and pricing behavior, we further assume that firms engage in a purely combative non-price competition context, in the sense that non-price activities by a firm expand the demand for its products by drawing existing customers away from rival products.

The analytical framework of this paper departs from the assumption of constant elasticity of substitution among goods, which is typically made in a Calvo-style model, and instead assumes a more generic specification, such as that used in Kimball (1995), that allows for demand functions featuring a non-constant price elasticity (quasi-kinked demand). Several reasons justify this modeling strategy. First, adopting Kimball preferences allows the obtaining in a relatively simple way the linkage between non-price competition activities by firms and product differentiation among goods of different producers. As we will see next, with non-constant elasticity of demand, changes in non-price activities that affect the distribution of market shares across firms in turn affect the elasticity of demand faced by each individual producers, and hence the degree of substitutability of their products. Second, an environment where firms face demand functions featuring a non-constant price elasticity appears to be the most appropriate theoretical ground for evaluating non-price competition in a model with nominal rigidities. In this context, in fact, a producer, in increasing its own relative price, faces a higher opportunity cost, as the loss of customers resulting from the downward sloping demand curve is amplified by the price elasticity being an increasing function of the relative price. In a such a circumstance, therefore, it should be potentially more convenient for a producer trying to boost profits to affect demand through non-price tools, which do not directly involve price movements.

Within this analytical framework, the joint role of non-price competition and firms' pricing policies in the determination of the aggregate price level is analyzed by focusing on the reducedform inflation dynamics represented by the New Keynesian Phillips curve. To preview our results, we find that non-price competition does affect inflation dynamics, by increasing the inflationmarginal cost coefficient. This result hinges on the property that, under very general assumptions, non-price competition generates a mechanism that dampens the overall degree of real rigidity in price-setting. In our framework, in fact, pricing and non-pricing policies are strategic complements, so that, through non-price tools, a firm mitigates the effect upon its market share made by price movements. This reduces the opportunity cost that price-setters face in changing their relative price, mitigates the degree of real rigidity and eventually increases the size of price changes. As a result, if firms engage in non-price competition, inflation becomes more sensitive to movements in marginal cost.

From the perspective of New Keynesian theory, our results are relevant because they show that allowance for non-price competition among firms generates a mechanism that dampens the overall impact of real rigidities on inflation dynamics. This issue is particularly important, as real rigidities have became popular among New Keynesian theorists precisely because they provide a mechanism to amplify the effect of nominal disturbances and, all else being equal, to reduce the size of the Phillip curve's slope. In light of these features, real rigidities in price-setting, also refereed to as strategic complementarities, are now recognized as important theoretical ingredients of modern-day New Keynesian models. For instance, Eichenbaum and Fisher (2007) have shown that extending the canonical Calvo model by assuming firm-specific capital and demand functions to have non-constant elasticity of demand (quasi-kinked demand) allows one to pin down a realistic 
degree of nominal rigidities. Smetz and Wouters (2007) have used quasi-kinked demands function in an estimated monetary DSGE model. Sbordone (2008) extends the Kimball model to study the effect of globalization on inflation dynamics. Our analysis casts some doubt regarding the robustness of such conclusions, showing that abstracting from non-price competition, as canonical model do, may potentially overstate the overall impact of strategic complementarities on inflation dynamics. This therefore suggests that enriching the New Keynesian framework to include nonprice competition among firms may be a promising feature in order to improve our understanding on the key determinants of inflation dynamics. This should be particularly true in economy, as the US one, in which non-price competition appears to be an important dimension of the inter-firm rivalry.

The paper is organized as follows. Section 2 describes the model economy and provides the main results; Section 3 concludes.

\section{A simple economy with non-price competition}

In this section we lay out a baseline framework that captures the key features of non-price competition in a context of nominal and real rigidities. The specific framework we develop is a variant of the canonical model discussed in Kimball (1995). The main difference is that in our model, firms may also engage in non-price competition by spending on activities that expand their customer bases. This modification results in non-trivial consequences for inflation dynamics, affecting in particular the inflation-marginal cost relationship. As a general result, we show that any activity by firms that boosts demand for their products, without directly affecting their prices, dampens at the same time the overall degree of real rigidities in price-settings.

\section{$2.1 \quad$ Households}

The economy consists in a continuum of differentiated goods index by $i \in[0,1]$, each produced by a monopolistically competitive firm and over which consumer preferences are defined. More specifically, the household takes utility from an object $C_{t}$, which is implicitly defined by a relation of the form

$$
\int_{0}^{1} \psi\left(\frac{b_{t}(i) c_{t}(i)}{C_{t}}\right) d i=1
$$

where $c_{t}(i)$ denotes the quantity consumed of variety $i ; \psi($.$) is an increasing and strictly concave$ function, with $\psi(1)=1$, while $b_{t}(i) \geq 0$ satisfies the following condition:

\section{Assumption 1.}

$$
b_{t}(i)=\nu\left(z_{t}(i)\right)
$$

where $\nu$ is a positive, strictly increasing and strictly concave function, with $\nu(1)=1 ; z_{t}(i)=$ $Z_{t}(i) / Z_{t}$ denotes firm $i$ 's non-price activities relative to the market average.

Equation (1) extends Kimball's (1995) preferences to an environment where firms engage in non-price competition. To embed this feature into the model, we follow Spence (1977) by assuming that consumers' preferences are endogenously determined, depending on the distribution of nonprice activities across firms. For each variety $i$, this linkage is controlled by the term $b_{t}(i)$, whose properties are restricted in order to guarantee that the desired requirements for non-price competition are fulfilled in this general setup. This feature will be apparent by deriving the demand 
curve for each individual variety. The latter is the solution to the dual problem of minimizing consumption expenditures subject to the aggregation constraint (1), that is:

$$
c_{t}(i)=\frac{C_{t}}{b_{t}(i)} \psi^{\prime-1}\left(\frac{P_{t}(i) C_{t}}{\lambda_{t} b_{t}(i)}\right)
$$

where $\psi^{\prime-1}$ denotes the inverse function of $\psi^{\prime}, P_{t}(i)$ is the price of good $i$, and $\lambda_{t}$ is the Lagrange multiplier for the constrain (1) which is implicitly defined as follows:

$$
\int_{0}^{1} \psi\left(\psi^{\prime-1}\left(\frac{P_{t}(i) C_{t}}{\lambda_{t} b_{t}(i)}\right)\right) d i=1
$$

For future reference, notice that here, in contrast with the standard Dixit-Stiglitz framework, the Lagrange multiplier, $\lambda_{t}$, does not need to coincide with the price index $P_{t}$. The latter is usually defined as the cost of a unit of the composite good, that is:

$$
P_{t}=\frac{1}{C_{t}} \int_{0}^{1} P_{t}(i) c_{t}(i) d i \equiv \int_{0}^{1} \frac{P_{t}(i)}{b_{t}(i)} \psi^{\prime-1}\left(\frac{P_{t}(i) C_{t}}{\lambda_{t} b_{t}(i)}\right) d i
$$

Given (3), the monotonically increasing behavior of $b_{t}(i)$ implies that the demand of each variety is also increasing in the producer's relative non-price activities. To see this, notice that differentiating the demand schedule $(3)$ with respect to $z_{t}(i)$ yields

$$
\frac{\partial c_{t}(i)}{\partial z_{t}(i)}=\frac{c_{t}(i)}{b_{t}(i)}\left(\varepsilon_{p, t}(i)-1\right) v^{\prime}\left(z_{t}(i)\right)
$$

where $\varepsilon_{p, t}(i)$ is the demand price elasticity for good $i$ which will be formally introduced shortly. Since for the firms' optimization problem to be well-defined it is required that $\varepsilon_{p, t}(i)>1$, we find that $\partial c_{t}(i) / \partial z_{t}(i)>0 \forall i \in[0,1]$.

This property hinges on the assumption that consumers' tastes are endogenously determined. In fact, in our framework the consumers' marginal utility of each variety is also increasing in the producer's relative expenditures for non-price competition. To see this, notice that applying the implicit function theorem to equation (1) in order to derive an expression for the marginal utility of each variety, and differentiating the resulting equation with respect to $z_{t}(i)$ yields:

$$
\frac{\partial^{2} C_{t}}{\partial c_{t}(i) \partial z_{t}(i)}=\frac{\psi^{\prime}\left(x_{t}(i)\right)}{D_{\psi}}\left[1-\frac{1}{\varepsilon_{p, t}(i)}\right] v^{\prime}\left(z_{t}(i)\right)>0 \forall i \in[0,1]
$$

where $D_{\psi}$ is a positive constant ${ }^{4}$ and $x_{t}(i)=\left(c_{t}(i) b_{t}(i)\right) / C_{t}$. Hence, any asymmetrical distribution of non-price activities across firms affects consumers' demand precisely because it modifies the consumers' marginal evaluation of each variety. For equal prices, in particular, a household will devote a higher fraction of its income in products whose producers spent the most to gain an advantage in the non-price competition in their market. Alternatively, the demand of each variety will increase in response to an increment in the producer's non-price expenditures.

\footnotetext{
${ }^{4}$ To see this, notice first that $D_{\psi}=\int_{0}^{1} \psi^{\prime}\left(x_{t}(i)\right) x_{t}(i) d i$. By assumption $\psi_{t}\left(x_{t}(i)\right)$ is a strictly increasing and strictly convex of function of $x_{t}(i)$, so the integrand $\psi^{\prime}\left(x_{t}(i)\right) x_{t}(i)$ is then a positive and continuous function. As such, the above integral is a positive real number.
} 
This feature has a natural interpretation in terms of the degree of substitutability among goods. Intuitively, we can think that non-price activities by a firm, such as marketing promotions or investment in quality, by attaching peculiar attributes to the product, increase the consumers' perceived differentiation with respect to rival products. Consider, for instance, a producer that increases its relative expenditures on non-price competition. In our framework, this directly affects the consumer's tastes, making that product more valuable in terms of utility. As such, the consumers' cost of switching from that good to another, for example, as the former becomes more expensive, increases. Equivalently, the degree of substitutability between that good and the rival products decreases. Because of this perception of product differentiation, consumers are then willing to pay a higher price for that good and, for a given price, the producer's market share increases.

As a second property, we note that the demand for each product is decreasing in the average expenditure for non-price competition. This is an immediate implication of the assumption that for any variety $i$, the factor $b_{t}(i)$ depends upon the producer's relative expenditures $z_{t}(i)$. In fact, direct differentiation of (3) yields:

$$
\frac{\partial c_{t}(i)}{\partial Z_{t}}=-\frac{c_{t}(i)}{Z_{t}}\left(\varepsilon_{p, t}(i)-1\right) \varepsilon_{b, z}(i)<0
$$

where $\varepsilon_{b, z}(i)>0$ denotes the percentage change in $b_{t}(i)$ resulting from a percentage variation of $z_{t}(i)$. Hence, our formulation captures the fact that firms engage in a combative non-price competition context in the sense that an increase in expenditure for non-price tools of a sufficiently large fraction of firms creates a negative externality on the demand faced by other firms. This means that in our framework non-price competition is a zero-sum game, since non-price activities by a firm increase demand by drawing existing consumers away from rival products. Therefore, any asymmetrical distribution in non-price activities merely redistributes demand among firms, thereby causing an asymmetrical distribution in market shares.

One important feature of the Kimball aggregator (1) is that it generalizes the standard DixitStiglitz preferences, ${ }^{5}$ allowing for a non-constant elasticity of demand with respect to relative price. Denoting the latter with $\varepsilon_{p, t}(i)$, one can easily prove the following:

$$
\varepsilon_{p, t}(i)=-\frac{\psi^{\prime}\left(x_{t}(i)\right)}{x_{t}(i) \psi^{\prime \prime}\left(x_{t}(i)\right)}
$$

which shows that the CES aggregator is in fact a special case of (1) obtained by specifying the function $\psi\left(x_{t}(i)\right)$ so that the ratio $\psi^{\prime}\left(x_{t}(i)\right) /\left[x_{t}(i) \psi^{\prime \prime}\left(x_{t}(i)\right)\right]$ is constant $\forall x_{t}(i)$. As Kimball (1995) has shown, it is always possible to find a specific functional form for $\psi\left(x_{t}(i)\right)$ that matches any desired dependence of the elasticity of demand on the firm's relative output. Here, in order to introduce strategic complementarity in price-setting, we are interested in the functional form for $\psi\left(x_{t}(i)\right)$ that generates 'quasi-kinked' demand functions, characterized by the property that for the firm at its normal market share, it is easier to lose customers by increasing its relative price than to gain customers by lowering its relative price. This requires that the price elasticity is decreasing in the firm's relative sales (market share). However, the assumptions we have made so far do not have any implications for the sign of $\varepsilon_{p, t}^{\prime}(i)$. Therefore, hereafter we confine our attention to functional forms satisfying the following condition:

\section{Assumption 2.}

$$
\frac{\partial \varepsilon_{p, t}(i)}{\partial m_{y, t}(i)}=\varepsilon_{p, t}^{\prime}(i) b_{t}(i)<0
$$

\footnotetext{
${ }^{5}$ The Dixit-Stiglitz preferences are obtained, as a special case, by setting $\psi\left(x_{t}(i)\right)=x_{t}(i)^{\varepsilon /(\varepsilon-1)}$, with $\varepsilon>1$.
} 
where $m_{y, t}(i)=c_{t}(i) / C_{t}$ is the firm $i$ 's market share, and $\varepsilon_{p, t}^{\prime}(i)=\partial \varepsilon_{p, t}(i) / \partial x_{t}(i)$.

The next proposition summarizes an important implication resulting from non-price competition in an environment where producers face quasi-kinked demand functions.

Proposition 1. Let the households' consumption aggregate be of the form (1). Then, for any functions $\psi\left(x_{t}(i)\right)$ and $b_{t}(i)$ satisfying assumptions 1-2, the demand price elasticity of each variety $i, \varepsilon_{p, t}(i)$, is decreasing in the producers' relative non-price activities.

Proof. In order to prove this statement, note first that,

$$
\begin{aligned}
\frac{\partial \varepsilon_{p, t}(i)}{\partial z_{t}(i)} & =\frac{\partial \varepsilon_{p, t}(i)}{\partial x_{t}(i)} \frac{\partial x_{t}(i)}{\partial b_{t}(i)} \frac{\partial b_{t}(i)}{\partial z_{t}(i)} \\
& =\varepsilon_{p, t}^{\prime}(i) m_{y, t}(i)\left(1+\frac{\partial c_{t}(i)}{\partial b_{t}(i)} \frac{b_{t}(i)}{c_{t}(i)}\right) v^{\prime}\left(z_{t}(i)\right) \\
& =\varepsilon_{p, t}^{\prime}(i) m_{y, t}(i) \varepsilon_{p, t}(i) v^{\prime}\left(z_{t}(i)\right)
\end{aligned}
$$

given that the assumption 1 requires $v^{\prime}\left(z_{t}(i)\right)>0$ and that $m_{y, t}(i)$ and $\varepsilon_{p, t}(i)$ are both strictly positive, this implies:

$$
\operatorname{sign}\left(\frac{\partial \varepsilon_{p, t}(i)}{\partial z_{t}(i)}\right)=\operatorname{sign}\left(\varepsilon_{p, t}^{\prime}(i)\right)
$$

Therefore, for any function $\psi\left(x_{t}(i)\right)$ that satisfies assumption 2 , it must be true that

$$
\frac{\partial \varepsilon_{p, t}(i)}{\partial z_{t}(i)}<0 \forall z_{t}(i)>0
$$

since $\operatorname{sign}\left(\varepsilon_{p, t}^{\prime}(i)\right)<0 \forall x_{t}(i)>0$.

Accordingly, for each variety $i$, the producer's relative expenditures for non-price competition not only shift the demand schedule but also reduce price elasticity. While the first effect is a direct consequence of assumption 1, the second is instead entirely due to assumption 2. As is apparent from equation (9), with CES preferences, an increase in the firm's relative non-price activities would just generate a parallel upward shift in the demand schedule without affecting the slope. Furthermore, the effect of non-price activities on the demand price elasticity uniquely depends upon the linkage between the latter and the firm's relative price. In fact, assuming strategic substitutability in price-setting ${ }^{6}$ would instead have the effect of making the demand price elasticity an increasing function of firm's non-price activities. Therefore, it turns out that in our framework assumption 2 is a necessary condition to obtain a positive linkage between the intensity of non-price competition and firms' market power.

\section{$2.2 \quad$ Firms}

In this model, firms make decisions on pricing policy, production plans and budgets for nonprice competition. In order to explicitly analyze the firms' behavior, we therefore require further assumptions concerning the technology available for producing goods, the type of market and technology characterizing non-price activities and the source of nominal rigidities. To this end, hereafter we confine our attention to a model economy satisfying the following two conditions:

\footnotetext{
${ }^{6}$ That is, assuming that $\partial \varepsilon_{p}(i) / \partial m_{y, t}(i)>0$.
} 
Assumption 3. Prices are set in staggered contracts with random duration as in Calvo (1983): in any period, each firm faces a constant probability $(1-\theta)$ of being able to re-optimize and charge a new price.

Assumption 4. There exists an economy-wide labor market, with nominal wage $W_{t}$, from which firms hire labor for the production of both consumption goods and non-price activities. All the firms have access to a common technology of the form $A_{t} f_{s}\left(h_{s, t}(i)\right)$ with $s=\{y, z\}$, where $f_{s}($.$) is$ a strictly increasing and concave function; $h_{s, t}$ denotes hours for producing goods $(s=y)$ or nonprice activities $(s=z)$, and $A_{t}$ is a (stochastic) factor that describes the evolution of technology.

Assumption 3 introduces nominal rigidities by assuming staggered prices a la Calvo; every period, only a fraction $(1-\theta)$ of the firms can set a new price, independently of the past history of price changes. Assumption 4 instead describes the technological structure of the model economy. It states that firms produce goods as well as non-price activities by using a common technology that requires only labor. While we could proceed by making rather general assumptions about the market for these non-price activities, we choose to simplify the analysis by assuming, as in Grossmann (2007), that firms produce these tools in-house. However, this choice is inconsequential to our main conclusions. ${ }^{7}$

The firms' optimization problem can be solved in an equivalent two-step procedure. In the first step, a firm chooses the amount of labor for the production of goods and non-price activities by minimizing the total cost function subject to technology constraints. Given assumption 4, the first-order conditions for an interior minimum are the following:

$$
\begin{aligned}
& \eta_{t}(i)=\frac{w_{t}}{A_{t} f_{y}^{\prime}\left(h_{y, t}(i)\right)} \\
& \varphi_{t}(i)=\frac{w_{t}}{A_{t} f_{z}^{\prime}\left(h_{z, t}(i)\right)}
\end{aligned}
$$

where $w_{t}$ denotes the real wage, while $\eta_{t}(i)$ and $\varphi_{t}(i)$ are the marginal costs for producing consumption goods and non-price activities, respectively. While we have assumed an economy-wide labor market, equation (10) indicates that decisions concerning demand of labor input are instead firmspecific. This feature implies that production marginal cost depends not only on economy-wide factors but also on the firm's own output. In a model based on the Calvo pricing mechanism, ${ }^{8}$ this generates strategic complementarity in price-setting that reduces the size of price changes and, all else being equal, lowers the sensitivity of inflation to marginal cost. To see why, take the example of a contractionary monetary shock. In this case, adjusters would find it convenient to reduce their prices in order to boost their profits. However, if marginal cost is firm-specific, adjusters trying to boost its sales by undercutting others would also be increasing their own production marginal cost. This reduces profits from undercutting, thereby making price-setters less inclined to undercut the fixed prices of their competitors. As a consequence, the size of price changes declines, thereby reducing the sensitivity of inflation to movements in real marginal costs.

In the second step, a firm seeks to maximize profits by choosing price and non-price expenditures, $Z_{t}(i)$. Given the cost-minimizing conditions, the instantaneous real profit at date $t$ for firm $i$ can then be written as

$$
\pi\left(p_{t}(i), Z_{t}(i), \xi_{t}\right)=p_{t}(i) y_{t}(i)-T C\left(Z_{t}(i), y_{t}(i), \xi_{t}\right)
$$

\footnotetext{
${ }^{7}$ One can easily show that this restriction is equivalent to assuming a perfectly competitive market for non-price activities, where producing firms use the same technology as an assumption 4.

${ }^{8}$ See Sbordone (2002) for further details.
} 
where $p_{t}(i)=P_{t}(i) / P_{t}$ is the firm relative price at date $t, T C($.$) is the cost function, \xi_{t}$ is a vector containing all the exogenous variables affecting profits, and $y_{t}(i)$ the demand curve for the good $i$ which, according to the households' expenditures minimization problem, is given by:

$$
y_{t}(i)=\frac{Y_{t}}{b_{t}(i)} \psi^{\prime-1}\left(\frac{P_{t}(i) Y_{t}}{\lambda_{t} b_{t}(i)}\right)
$$

where $Y_{t}$ denotes aggregate demand.

It should be noted here that the assumptions we have made so far are not enough to guarantee that the profit function attains its maximum at some interior point. Therefore, in order to make the analysis of the first order conditions meaningful, hereafter we restrict the space of admissible functions by considering only functional forms for $\psi\left(x_{t}(i)\right)$ and $b_{t}(i)$ that satisfy the following condition:

Assumption 5. The profit $\pi\left(p_{t}(i), Z_{t}(i), \xi_{t}\right)$ is a single-picked function of its first two arguments, with a maximum at some positive vector $\left(p_{t}(i), Z_{t}(i)\right)$ for any values of its other arguments.

Given (12), the second step of the firms' optimization problem therefore consists of the following program:

$$
\max \sum_{k=t}^{\infty} E_{t}\left\{Q_{t, t+k}^{r}\left[P_{t+k}(i) y_{t+k}(i)-T C\left(Z_{t+k}(i), y_{t+k}(i), \xi_{t+k}\right)\right]\right\}
$$

s.t.

$$
\begin{aligned}
y_{t+k}(i) & =\frac{Y_{t+k}}{b_{t+k}(i)} \psi^{\prime-1}\left(\frac{p_{t+k}(i) Y_{t+k}}{\lambda_{t+k} b_{t+k}(i)}\right) \\
b_{t+k}(i) & =\nu\left(\frac{Z_{t+k}(i)}{Z_{t+k}}\right) \\
p_{t+k}(i) & = \begin{cases}p_{t+k-1}(i) \Pi_{t+k}^{-1} & \text { with probability } \theta \\
p_{t+k}^{*}(i) & \text { with probability }(1-\theta)\end{cases}
\end{aligned}
$$

where $Q_{t, t+k}^{r}=Q_{t, t+k} \Pi_{t+k}$ is the real stochastic discount factor ${ }^{9}, \Pi_{t+k}=P_{t+k} / P_{t+k-1}$ is the inflation rate at date $t+k$, and $p_{t+k}^{*}(i)$ denotes the optimal relative price chosen by a resetting firm at date $t+k$. The first-order condition with respect to non-price activities is given by:

$$
\frac{\partial y_{t}(i)}{\partial Z_{t}(i)} p_{t}(i)=\varphi_{t}(i)+\frac{\partial y_{t}(i)}{\partial Z_{t}(i)} \eta_{t}(i)
$$

Accordingly, in order to maximize profit, a firm chooses the non-price competition budget such that the increase in revenues resulting from an additional unit of non-price expenditures is equal to the corresponding increase in total cost. This equation implies an optimal rule for non-price activities in terms of its ratio to total sales. To see this, notice that differentiating (13) with respect to $Z_{t}(i)$, plugging the resulting equation into (14) to substitute out the derivative of demand with respect to non-price activities, and rearranging the terms yields:

$$
\frac{Z_{t}(i)}{y_{t}(i)}=\varepsilon_{z, t}(i)\left(\frac{p_{t}(i)-\eta_{t}(i)}{\varphi_{t}(i)}\right)
$$

\footnotetext{
${ }^{9}$ Under the maintaining assumptions of perfect financial market and households that holds the ownership of the firms, the stochastic discount factor is defined as:

$$
Q_{t, t+k}^{r}=\beta^{k} \frac{\Lambda_{t+k}}{\Lambda_{t}}
$$

where $\beta$ is the subjective discount factor and $\Lambda_{t+k}$ is the marginal evaluation of consumption at date $t+k$.
} 
where $\varepsilon_{z, t}(i)$ denotes the elasticity of the demand function with respect to spending for non-price tools, which in turn is given by:

$$
\varepsilon_{z, t}(i)=\left(\varepsilon_{p, t}(i)-1\right) \varepsilon_{b, z}(i)
$$

For any firm $i$, the intensity of non-price competition is therefore proportional to the ratio of average net revenues from sales to non-price marginal cost, where the factor of proportionality is given by the elasticity of demand with respect to non-price tools, $\varepsilon_{z, t}(i)$. Interesting, this equation reveals that firms' pricing and non-pricing policies are in fact directly related. According to (15), a firm will find it convenient to increase its non-price budget in response to an increase in the unit net revenue from sales caused by a higher relative price. Using the terminology of Iwasaki et al. (2008), this means that in our framework, firms play a super-modular game, since their pricing and non-pricing policies are complementary strategies. ${ }^{10}$

The first-order condition for price-setting is given by

$$
\sum_{k=0}^{\infty} \theta^{k} E_{t}\left\{\frac{Q_{t, t+k}^{r} y_{t+k}(i)}{p_{t+k}(i)}\left(\varepsilon_{p, t+k}(i)-1\right)\left[p_{t+k}(i)-\mu_{t+k}(i) \eta_{t+k}(i)\right]\right\}=0
$$

where $\mu_{t+k}(i)$ denotes the firm's desired markup, ${ }^{11}$ which is given as follows:

$$
\mu_{t+k}(i)=\frac{\varepsilon_{p, t+k}(i)}{\varepsilon_{p, t+k}(i)-1}
$$

The presence of a demand featuring a non-constant price elasticity modifies the optimal choice of a price setter along a crucial dimension; the desired markup becomes an increasing function of the firm's relative output. As it is well-known (see Woodford (2003)), for a re-optimizing firm, this mechanism increases the cost of deviating from the prices charged by others, making firms more reluctant to change their prices when this action is allowed. As we will see next, in the aggregate this mechanism reduces the sensitivity of inflation to marginal costs, leading to a flattened Phillips curve. However, this result is obtained under the crucial assumption that firms compete for the market with no instruments but their relative output prices. As we have seen before, extending the Kimball framework to an environment with non-price competition implies that the demand price elasticity is by itself a decreasing function of non-price activities, and the firm's desired mark-up is thus increasing in these tools. This clearly affects the firms' pricing behavior, since it modifies the opportunity cost of changing relative prices. However, the extent to which this mechanism affects the inflation dynamics depends, in turn, on the kind of relation existing between pricing and non-pricing policies. This is what is analyzed in the next section.

\subsection{The New Keynesian Phillips Curve}

To derive an expression for the New Keynesian Phillips curve in the context of non-price competition, we restrict the attention to a linear approximation of the equilibrium dynamics around a zero-inflation steady-state. Hereafter, a hat on a variable denotes the log deviation of the original variable with respect to its steady state, while a variable evaluated at the steady-state is indicated by suppressing indexes $i$ and $t$ from the original variable.

\footnotetext{
${ }^{10}$ Super-modular games are a general class of noncooperative games where $n$ players simultaneously choose a set of strategies. See Milgrom and Roberts (1990) for further details. Iwasaki el al. (2008) discuss the general property of advertising that unequivocally leads to a supermodular game in the context of an oligopolistic market in which firms simultaneously choose their advertising budgets and pricing policy.

${ }^{11}$ That is the optimal mark-up a firm would have chosen in the context of flexible prices.
} 
Log-linearizing the first-order condition for the optimal price chosen by a resetting firm yields: ${ }^{12}$

$$
\Gamma \sum_{k=0}^{\infty}(\theta \beta)^{k} E_{t} \tilde{p}_{t+k}(i)=\sum_{k=0}^{\infty}(\theta \beta)^{k} E_{t} \hat{\eta}_{t+k}+\left(\varepsilon_{p} \varepsilon_{\mu}+\left(\varepsilon_{p}-1\right) s_{y}\right) \sum_{k=0}^{\infty}(\theta \beta)^{k} \varepsilon_{b, z} E_{t} \tilde{z}_{t+k}(i)
$$

where $\varepsilon_{\mu}>0$ is the elasticity of the desire markup function with respect to the firm market share, ${ }^{13}$ $\beta \in(0,1)$ denotes the long-run stochastic discount factor, $s_{y}>0$ is the steady-state elasticity of the production marginal cost with respect to firms' relative output, $\Gamma=\left[1+\varepsilon_{p}\left(\varepsilon_{\mu}+s_{y}\right)\right], \tilde{p}_{t+k}(i)$ $=\hat{p}_{t}^{*}(i)-\hat{P}_{t+k}$ and $\tilde{z}_{t+k}(i)=\hat{Z}_{t+k}(i)-\hat{Z}_{t+k}$.

The standard case without non-price competition can be recovered from the previous equation by setting $\varepsilon_{b, z}$ equal to zero. In such a case, with standard manipulation, one can obtain the following familiar form of inflation dynamics as a function of the expected future inflation and aggregate marginal cost:

$$
\hat{\pi}_{t}=\beta E_{t} \hat{\pi}_{t+1}+\zeta \hat{\eta}_{t}
$$

where $\zeta$ is defined as:

$$
\zeta=\frac{(1-\beta \theta)(1-\theta)}{\theta}\left(\frac{1}{1+\varepsilon_{p}\left(\varepsilon_{\mu}+s_{y}\right)}\right)
$$

Equation (21) formalizes the effect of real rigidities in price-setting on inflation dynamics. The slope $\zeta$ becomes the product of two terms, where the first corresponds to the slope we would obtain in the standard Dixit-Stiglitz case (i.e., $\left.\varepsilon_{\mu}=0\right)$ with a constant return to scale $\left(s_{y}=0\right)$, while the second is known as the strategic complementarity term. Hence, in our setup there are two channels through which real rigidities affect the inflation-marginal cost relation: $(i)$ the sensitivity of the firm's desired markup to relative prices, $\varepsilon_{\mu}$; $(i i)$ the sensitivity of marginal cost to the firm's relative output, $s_{y}$. In both cases, the effect is stronger with increases in demand price elasticity, $\varepsilon_{p}$.

Returning to our point, to precisely evaluate how the presence of non-price competition affects inflation dynamics, we first need to model the evolution of the firm $i$ 's relative expenditures for non-price activities. In fact, equation (19) involves the latter at a sequence of future dates, which in turn depends upon the optimal policy (14). Therefore, using the theory we have developed in the previous section, we find a result of the following form.

Proposition 2. Let the households' consumption aggregate be of the form (1), and suppose that the model economy has the structure described by assumptions 3 and 4. Then, for any functions $\psi(x)$ and $b_{t}(i)$ satisfying assumptions 1,2 and 5, the New Keynesian Phillips curve has the representation:

$$
\hat{\pi}_{t}=\beta E_{t} \hat{\pi}_{t+1}+\zeta_{n p} \hat{\eta}_{t}
$$

with:

$$
\zeta_{n p}=\frac{(1-\beta \theta)(1-\theta)}{\theta}\left\{\frac{1}{1+\varepsilon_{p}\left[\left(1-\phi_{0}\right) \varepsilon_{\mu}+\left(1-\phi_{1}\right) s_{y}\right]}\right\}
$$

\footnotetext{
${ }^{12}$ See the Appendix for further details on the derivation.

${ }^{13}$ More precisely, $\varepsilon_{\mu}(i)$ denotes the elasticity of the markup function with respect to $x_{t}(i)$. However, denoting with $\varepsilon_{\mu, m_{y, t}}(i)$ the elasticity with respect to firm $i$ 's market share, the following equality holds:

$$
\varepsilon_{\mu, m_{y, t}}(i)=\varepsilon_{\mu}(i) b_{t}(i)
$$

so that at the steady-state the two expressions coincide.
} 
where the coefficients $\phi_{0}$ and $\phi_{1}$ are strictly positive functions of the model structural parameters, such that $\phi_{0}>\phi_{1}$.

In addition, the slope $\zeta_{n p}$ possess the following properties:

(i) $\zeta_{n p}>\zeta$, where $\zeta$ is defined as in (21).

(ii) $\frac{\partial \zeta_{n p}}{\partial \varepsilon_{\mu}}<0$. Moreover:

$$
\zeta_{n p}>\frac{(1-\theta \beta)(1-\theta)}{\theta}\left\{\frac{\varepsilon_{b, z}^{2} \varepsilon_{p}}{-v^{\prime \prime}(1)+\varepsilon_{b, z}\left[s_{y} \varepsilon_{b, z}+s_{z}+2 \varepsilon_{b, z}\right]}\right\}>0 \forall \varepsilon_{\mu} \in\left(\varepsilon_{\mu}^{*}, \infty\right)
$$

where $\varepsilon_{\mu}^{*}=\inf _{\varepsilon_{\mu}} \mathcal{B}$, with $\mathcal{B} \subseteq \mathbb{R}_{+}$is a set of real numbers defined as in the appendix. ${ }^{14}$

Proof. See the appendix.

Several remarks are in order. First of all, the proposition confirms that for a firm, pricing and non-pricing policies are strategic complements. ${ }^{15}$ As shown in the Appendix, the firm $i$ 's relative expenditures on non-price activities can be expressed as a function of its own relative price as:

$$
\tilde{z}_{t}(i)=\phi_{z} \tilde{p}_{t}(i)
$$

where $\phi_{z}$ is a strictly positive function of the model's structural parameters. ${ }^{16}$ For any firm $i$, therefore, relative spending in non-price activity accommodates movements in relative prices. The elasticity $\phi_{z}$ measures in particular the extent to which a firm manages its non-price policy in order to offset real rigidities in price-settings. ${ }^{17}$ In fact, it is possible to show that without assuming firm-specific marginal costs and quasi-kinked demand functions, the coefficient $\phi_{z}$ is equal to zero, and, up to a order linear approximation, the firms' expenditures for non-price competition are independent of their relative prices. ${ }^{18}$

One way to think about this is that strategic complementarities strengthen firms' incentives to engage in non-price competition. To see this, suppose that a price setter deviates from the flexible price equilibrium by charging a higher price. This immediately increases the demand price elasticity, thus amplifying the loss of customers resulting from the downward-sloping demand schedule. At the same time, because of the lower market share, marginal cost decreases, and the production of one unit of consumption goods becomes less expensive. In such a circumstance, the firm's incentive to increase its relative expenditures on non-price tools strengthens. On the one hand, because of the negative effect on the demand price elasticity, by increasing the relative expenditures on non-price tools, a firm may partially offset the loss of customers caused by the

\footnotetext{
${ }^{14}$ Here, the coefficient $s_{z}$ denotes the long-run elasticity of non-price average marginal cost, while v" (1) denotes the second derivative of $b_{t}(i)$ evaluated at the steady-state.

${ }^{15}$ Given that $\varepsilon_{b, z}>0$, this follows by combining properties (i) of proposition with equation (19).

${ }^{16}$ See the appendix for further details

${ }^{17}$ It is interesting to note that the elasticity $\phi_{z}$ can be decomposed as follows:

$$
\phi_{z}=\phi_{\varepsilon}+\phi_{s y}
$$

The coefficient $\phi_{\varepsilon}$ measures the extent to which the optimal investment in non-price tools moves in order to compensate for the impact of the relative prices on the demand price elasticity. The coefficient $\phi_{s y}$ instead relates movements in non-price activities to variation in the marginal cost for producing consumption goods.

${ }^{18}$ In such a case, fluctuations in expenditures for non-price tools are only due to aggregate shocks affecting the opportunity cost and benefits of investing in this tools.
} 
higher relative price. On the other hand, the lower marginal cost for producing goods increases the marginal revenue of non-price activities, therefore making the latter more convenient.

As a second result, we note that in our framework, it is again possible to derive an expression that relates, as in the canonical model, the inflation rate to the average marginal cost and the expected future inflation. ${ }^{19}$ However, all else being equal, if firms engage in non-price competition, we find that the sensitivity of the inflation rate to marginal cost increases. ${ }^{20}$ Hence, by amplifying the overall response of inflation to output, non-price competition among firms does affect inflation dynamics.

To get an intuition for this result, notice that the interaction between firms' pricing behavior and non-price policy generates a mechanism that dampens the degree of strategic complementarities in price-setting. In fact, by comparing the slope coefficient $\zeta_{n p}$ with the one we obtain in the Kimball model, we note that while the nominal rigidities term is exactly the same, the real rigidities term is instead larger in our framework. This is an immediate implication of non-price policy being strategically complementary to the firm's pricing behavior. In fact, by accommodating the pricing policy with non-price tools, a firm essentially mitigates the effect upon its market share of movements in its relative price. This follows by noticing that, for each variety $i$, the producer's market share is given by:

$$
\hat{y}_{t}(i)-\hat{Y}_{t}=\left(-\varepsilon_{p}+\varepsilon_{z} \phi_{z}\right) \tilde{p}_{t}(i)
$$

Accordingly, with non-price competition, the firm's relative output becomes less sensitive to movements in its relative price. ${ }^{21}$ As a consequence, the firms' desired markup and its marginal cost for producing goods react less to movements in relative output price, making the profit function less steep around the point at which everybody charges the same price. Hence, the firms' opportunity cost to move their relative output prices, when this is allowed, declines, thus amplifying the size of price changes. As a result, if firms engage in non-price competition, inflation becomes more sensitive to movements in the real marginal cost.

Third, although the economic environment is characterized by real rigidities, we note that in our framework, the price-setting decision of different producers might become strategic substitutes. This feature is particularly striking, since in the Kimball model this is only possible by assuming that the price elasticity of demand decreases in relative prices. To see this, take for simplicity the case in which the non-constant elasticity of demand is the only source of real rigidity, and notice that the firms' desired markup reads as:

$$
\hat{\mu}_{t}(i)=\varepsilon_{\mu} \varepsilon_{p}\left[\varepsilon_{b, z} \phi_{z}-1\right] \tilde{p}_{t}(i)
$$

Strategic complementarity in price-setting implies that the elasticity of the firm's desired markup with respect to its relative output price is negative. Equation (26) shows that this requirement is not obviously satisfied if firms engage in non-price competition. In fact, the factor $\varepsilon_{b, z} \phi_{z}$ does not necessarily need to be lower than one. As such, producers may face strategic complementarity in price-setting, despite the fact that we have assumed that the elasticity of demand is increasing in the firms' relative prices. In such a circumstance, the dampening effect of non-price competition would completely offset real rigidity in price-setting, thereby leading to an inflation-marginal cost coefficient even larger than the Dixit-Stiglitz one.

Fourth, the slope $\zeta_{n p}$ is a bounded and decreasing function of the elasticity $\varepsilon_{\mu} \cdot{ }^{22}$ Unlike the Kimball model, however, in our framework, the lower bound is strictly positive. This property

\footnotetext{
${ }^{19}$ The New Keynesian Phillips Curve with non-price competition and the standard one are therefore observationally equivalent.

${ }^{20}$ See property (i) of the proposition.

${ }^{21}$ This is true since the factor $\varepsilon_{z} \phi_{z}$ is positive.

${ }^{22}$ This follows from property (ii) of the proposition.
} 
has two important and related implications that contrast with the canonical framework : $(i)$ the overall impact of quasi-kinked demand functions on the persistence of the real effects of monetary policy shocks is bounded; and $(i i)$ it is not obvious whether, for plausible calibrations of all the remaining parameters, it is still possible to pin down a realistic value for the slope coefficient $\zeta_{n p}$ by adjusting accordingly the elasticity $\varepsilon_{\mu}$.

Oppositely ${ }^{23}$ assuming Kimball preferences in Calvo-style models without non-price competition, by allowing for a non-constant elasticity of demand, generates a kind of strategic complementary that instead allows one to get any desired level of persistence in the real effect of monetary policy shock and, for any given estimate of the Phillip's curve slope, to pin down a more plausible degree of nominal rigidity. This feature is apparent from equation (21), which shows that the slope coefficient $\zeta$ is strictly decreasing in the elasticity of the markup function, $\varepsilon_{\mu}$, converging to zero as the latter goes to infinity. As such, for any given value of the Calvo probability $\theta$, it is always possible to pin down $\varepsilon_{\mu}$ in order to set the slope coefficient $\zeta$ to any desired level.

This property does not hold true in our framework, since with non-price competition, an increase in the elasticity $\varepsilon_{\mu}$ generates two different effects: $(i)$ as in standard models, each pricesetter faces a higher opportunity cost in changing price, since demand becomes more steep around each firm's normal market share; and $(i i)$ for each firm, an additional unit of relative spending toward non-price competition becomes more effective in lowering the demand price elasticity. In fact, in the equilibrium in which everybody charges the same price, the following relation holds:

$$
\left.\frac{\partial \varepsilon_{p}(i)}{\partial \tilde{z}_{t}(i)}\right|_{x_{t}(i)=1}=-\varepsilon_{\mu} \varepsilon_{p}^{2} \varepsilon_{z}
$$

which shows that the effect of non-price activities on the elasticity of demand is stronger as $\varepsilon_{\mu}$ increases. $^{24}$ The second effect, missing in canonical models, offsets the first one, thereby attenuating the overall impact upon the inflation-marginal cost coefficient of higher values of $\varepsilon_{\mu}$.

As a final remark, we note that the coefficient $\phi_{0}$ is greater than $\phi_{1}$ for any admissible vector of the model's structural parameters. This means that the dampening effect of non-price competition affects more real rigidity coming from quasi-kinked demand functions than that caused by decreasing returns to scale. In fact, as is apparent from equation (23), the two coefficients $\phi_{0}$ and $\phi_{1}$ respectively capture the partial effect of non-price competition on the inflation-marginal cost relationship through the real rigidity components $\varepsilon_{\mu}$ and $s_{y} \cdot{ }^{25}$

\footnotetext{
${ }^{23}$ See for instance Woodford (2003).

${ }^{24}$ Equation (27) is derived as follows. First, evaluating equation (9) at the steady state implies:

$$
\left.\frac{\partial \varepsilon_{p}(i)}{\partial \tilde{z}_{t}(i)}\right|_{x_{t}(i)=1}=\left.\frac{\partial \varepsilon_{p}(i)}{\partial x_{t}(i)}\right|_{x_{t}(i)=1} \varepsilon_{p} \varepsilon_{b, z}
$$
}

Second, making use of the definition of $\varepsilon_{\mu}$, we find:

$$
\left.\frac{\partial \varepsilon_{p}(i)}{\partial x_{t}(i)}\right|_{x_{t}(i)=1}=-\varepsilon_{\mu}\left(\varepsilon_{p}-1\right) \varepsilon_{p}
$$

Finally, combining together these two expressions and using (16) in the resulting equation yields (27).

${ }^{25}$ To see this compare equation (21) with equation (23). 


\section{Conclusion}

This paper has analyzed the implications of non-price competition among firms in a Calvostyle model characterized by strategic complementarity in price-setting. Under very general assumptions, it has been shown that any activity by firms that expands their customer bases without directly affecting their prices dampens at the same time the degree of real rigidity in price-setting. This provides an answer to the main question of this paper: by increasing the inflation-marginal cost coefficient, non-price competition among firms does affect inflation dynamics.

Among other things, the theoretical results provided in this paper highlight the fact that nonprice competition generates a mechanism that dampens the overall impact of real rigidities on the inflation-marginal cost coefficient. This effect could be strong enough to completely offset real rigidity in price-setting. In such an extreme case, although the model economy is characterized by quasi-kinked demand functions and local factors market, one would find an inflation marginal cost coefficient even larger than the Dixit-Stiglitz one. This suggests that abstracting from non-price competition, as canonical models do, may potentially overstate the overall impact of real rigidities on inflation dynamics. This issue is particularly important, as real rigidities have became popular among New Keynesian theorists precisely because they provide a mechanism to amplify the effect of nominal disturbances and, all else being equal, to reduce the size of the Phillip curve's slope. Our analysis casts some doubt regarding the robustness of such conclusions, at least with respect to alternative specifications of the firms' competition. However, the overall impact of non-price competition on inflation dynamics depends upon different mechanisms whose relative strength in turn depends on the model's parametrization. Addressing this issue therefore requires the specification and calibration of a full-fledged model through which it could be possible to evaluate the implication for different sources of real rigidity. This issue goes far beyond the scope of this paper, and we have therefore left it for future research. 


\section{A Appendix. Proof of proposition 2}

\section{I) The New Keynesian Phillips curve}

We will first show that in our framework it is possible to derive a New Keynesian Phillips curve of the form

$$
\hat{\pi}_{t}=\beta E_{t} \hat{\pi}_{t+1}+\zeta_{n p} \hat{\eta}_{t}
$$

where

$$
\zeta_{n p}=\frac{(1-\beta \theta)(1-\theta)}{\theta}\left\{\frac{1}{1+\varepsilon_{p}\left[\left(1-\phi_{0}\right) \varepsilon_{\mu}+\left(1-\phi_{1}\right) s_{y}\right]}\right\}
$$

\section{Step 1. Deriving equation (19)}

Let us start by noticing that in the non-stochastic steady state with zero inflation the following conditions hold:

$$
\begin{gathered}
\eta_{s}=\frac{1}{\mu_{s}} \equiv \frac{\left(\varepsilon_{p}-1\right)}{\varepsilon_{p}} \\
Q_{s, s+k}^{r}=\beta^{k}
\end{gathered}
$$

where $\eta_{s}$ and $\mu_{s}$ are respectively the long-run average production marginal cost and average mark-up, while $Q_{s, s+k}^{r}$ is the stochastic discount factor evaluated at the steady state. Plugging these relationships into the log-linearized first order condition for price-setters yields:

$$
\sum_{k=0}^{\infty}(\theta \beta)^{k} E_{t} \tilde{p}_{t+k}(i)=\sum_{k=0}^{\infty}(\theta \beta)^{k} E_{t} \hat{\eta}_{t+k}(i)+\sum_{k=0}^{\infty}(\theta \beta)^{k} E_{t} \hat{\mu}_{t+k}(i)
$$

Our next goal is to find an expression for both the firm's desired mark-up, $\hat{\mu}_{t}(i)$, and the firm's production marginal cost, $\hat{\eta}_{t}(i)$. Using equation (18), one can easily prove the following:

$$
\hat{\mu}_{t}(i)=-\frac{\hat{\varepsilon}_{p, t}(i)}{\left(\varepsilon_{p}-1\right)}
$$

where $\hat{\varepsilon}_{p, t}(i)$ is the log-linearized elasticity of demand. The latter is given by:

$$
\begin{aligned}
\hat{\varepsilon}_{p, t}(i) & =\left.\frac{\partial \varepsilon_{p, t}(i)}{\partial x_{t}(i)}\right|_{x_{t}(i)=1} \frac{\left[\left(\hat{y}_{t}(i)-\hat{Y}_{t}\right)+\varepsilon_{b, z} \tilde{z}_{t}(i)\right]}{\varepsilon_{p}} \\
& =-\varepsilon_{\mu}\left(\varepsilon_{p}-1\right)\left[\left(\hat{y}_{t}(i)-\hat{Y}_{t}\right)+\varepsilon_{b, z} \tilde{z}_{t}(i)\right]
\end{aligned}
$$

where the last equality follows by using the definition of $\varepsilon_{\mu}$ to substitute out the derivative $\partial \varepsilon_{p, t}(i) / \partial x_{t}(i)$. An expression for the firm $i$ 's log-linearized market share, $\hat{y}_{t}(i)-\hat{Y}_{t}$, can be derived from (3) as:

$$
\hat{y}_{t}(i)-\hat{Y}_{t}=-\varepsilon_{p} \tilde{p}_{t}(i)+\varepsilon_{b, z}\left(\varepsilon_{p}-1\right) \tilde{z}_{t}(i)
$$

Therefore:

$$
\begin{gathered}
\hat{\varepsilon}_{p, t}(i)=-\varepsilon_{\mu}\left(\varepsilon_{p}-1\right) \varepsilon_{p}\left(\varepsilon_{b, z} \tilde{z}_{t}(i)-\tilde{p}_{t}(i)\right) \\
\hat{\mu}_{t}(i)=\varepsilon_{\mu} \varepsilon_{p}\left(\varepsilon_{b, z} \tilde{z}_{t}(i)-\tilde{p}_{t}(i)\right)
\end{gathered}
$$

Next, in order to find an expression for the firm specific production marginal cost, it is convenient to rewrite equation (10) as follows:

$$
\eta_{t}(i)=\frac{w_{t}}{A_{t}} \Phi_{y}\left(\frac{y_{t}(i)}{A_{t}}\right)
$$

where

$$
\Phi_{y}\left(\frac{y_{t}(i)}{A_{t}}\right)=\frac{1}{f_{y}^{\prime}\left(f_{y}^{-1}\left(\frac{y_{t}(i)}{A_{t}}\right)\right)}
$$


This formulation allows to express the elasticity of production marginal cost with respect to the firm's output, $s_{y, t}(i)$ as follows:

$$
s_{y, t}(i)=\left[\frac{\Phi_{y}^{\prime}\left(\frac{y_{t}(i)}{A_{t}}\right)}{A_{t} \Phi_{y}\left(\frac{y_{t}(i)}{A_{t}}\right)}\right] y_{t}(i)
$$

while the average marginal production cost can be defined as:

$$
\eta_{t}=\frac{w_{t}}{A_{t}} \int_{0}^{1} \Phi_{y}\left(\frac{y_{t}(i)}{A_{t}}\right) d i
$$

Log-linearizing equations (A.5) and (A.7) and solving for $\hat{\eta}_{t}(i)$ yields:

$$
\hat{\eta}_{t}(i)=\hat{\eta}_{t}+s_{y}\left(\hat{y}_{t}(i)-\hat{Y}_{t}\right)
$$

Therefore, using (A.2) we can express the firm's specific production marginal cost as:

$$
\hat{\eta}_{t}(i)=\hat{\eta}_{t}+s_{y}\left[\left(\varepsilon_{p}-1\right) \varepsilon_{b, z} \tilde{z}_{t}(i)-\varepsilon_{p} \tilde{p}_{t}(i)\right]
$$

Finally, substituting equations (A.4) and (A.8) into (A.1) and rearranging the resulting equation yields:

$$
\Gamma \sum_{k=0}^{\infty}(\theta \beta)^{k} E_{t} \tilde{p}_{t+k}(i)=\sum_{k=0}^{\infty}(\theta \beta)^{k} E_{t} \hat{\eta}_{t+k}+\left(\varepsilon_{p} \varepsilon_{\mu}+\left(\varepsilon_{p}-1\right) s_{y}\right) \sum_{k=0}^{\infty}(\theta \beta)^{k} \varepsilon_{b, z} E_{t} \tilde{z}_{t+k}(i)
$$

where $\Gamma=\left[1+\varepsilon_{p}\left(\varepsilon_{\mu}+s_{y}\right)\right]$.

\section{Step 2. Finding an expression for $\tilde{\mathbf{z}}_{\mathbf{t}}(\mathbf{i})$}

To model the evolution of the relative spending for non-price competition it is convenient to substitute (6) into (14) in order to rewrite the optimal policy for non-price tools as follows:

$$
\frac{y_{t}(i)}{v\left(z_{t}(i)\right)}\left(\varepsilon_{p, t}(i)-1\right) v^{\prime}\left(z_{t}(i)\right)\left(p_{t}(i)-\eta_{t}(i)\right)=\varphi_{t}(i)
$$

By log-linearizing this expression, after a bit of algebra, one obtains:

$$
\varepsilon_{p}^{2} \varepsilon_{\mu} \tilde{p}_{t}(i)-\left[\frac{\varepsilon_{p}^{2} \varepsilon_{\mu} \varepsilon_{b, z}^{2}-v^{\prime \prime}(1)+\varepsilon_{b, z}^{2}\left(2-\varepsilon_{p}\right)}{\varepsilon_{b, z}}\right] \tilde{z}_{t}(i)-\left(\varepsilon_{p}-1\right) \hat{\eta}_{t}(i)=\hat{\varphi}_{t}(i)
$$

From this expression take the average across all the firm and subtract the resulting equation to find:

$$
\varepsilon_{p}^{2} \varepsilon_{\mu} \tilde{p}_{t}(i)-\left[\frac{\varepsilon_{p}^{2} \varepsilon_{\mu} \varepsilon_{b, z}^{2}-v^{\prime \prime}(1)+\varepsilon_{b, z}^{2}\left(2-\varepsilon_{p}\right)}{\varepsilon_{b, z}}\right] \tilde{z}_{t}(i)-\left(\varepsilon_{p}-1\right)\left(\hat{\eta}_{t}(i)-\hat{\eta}_{t}\right)=\left(\hat{\varphi}_{t}(i)-\hat{\varphi}_{t}\right)
$$

which, by using equation (A.8) to work out $\left(\hat{\eta}_{t}(i)-\hat{\eta}_{t}\right)$, can be equivalently rewritten as follows:

$$
\left[\varepsilon_{p}^{2} \varepsilon_{\mu}+\varepsilon_{p}\left(\varepsilon_{p}-1\right) s_{y}\right] \tilde{p}_{t}(i)-\left[\frac{\varepsilon_{p}^{2} \varepsilon_{\mu} \varepsilon_{b, z}^{2}-v^{\prime \prime}(1)+\varepsilon_{b, z}^{2}\left(2-\varepsilon_{p}\right)+\varepsilon_{b, z}^{2}\left(\varepsilon_{p}-1\right)^{2} s_{y}}{\varepsilon_{b, z}}\right] \tilde{z}_{t}(i)=\left(\hat{\varphi}_{t}(i)-\hat{\varphi}_{t}\right)
$$

As we have done for the marginal production cost, we can use (11) to express $\varphi_{t}(i)$ as:

$$
\varphi_{t}(i)=\frac{w_{t}}{A_{t}} \Phi_{z}\left(\frac{Z_{t}(i)}{A_{t}}\right)
$$


so that the elasticity $s_{t, z}(i)$ and the average marginal cost for producing non-price competition tools, $\varphi_{t}$ are respectively given by:

$$
\begin{gathered}
s_{z, t}(i)=\left[\frac{\Phi_{z}^{\prime}\left(\frac{Z_{t}(i)}{A_{t}}\right)}{A_{t} \Phi_{z}\left(\frac{Z_{t}(i)}{A_{t}}\right)}\right] Z_{t}(i) \\
\varphi_{t}=\frac{w_{t}}{A_{t}} \int_{0}^{1} \Phi_{z}\left(\frac{Z_{t}(i)}{A_{t}}\right) d i
\end{gathered}
$$

Therefore, log-linearizing equations (A.11) and (A.13) to obtain an expression for $\left(\hat{\varphi}_{t}(i)-\hat{\varphi}_{t}\right)$, substituting the resulting equation into (A.10) and solving for $\tilde{z}_{t}(i)$, yields:

$$
\tilde{z}_{t}(i)=\phi_{z} \tilde{p}_{t}(i)
$$

where

$$
\phi_{z}=\frac{\varepsilon_{b, z}\left[\varepsilon_{p}^{2} \varepsilon_{\mu}+\varepsilon_{p}\left(\varepsilon_{p}-1\right) s_{y}\right]}{\varepsilon_{p}^{2} \varepsilon_{\mu} \varepsilon_{b, z}^{2}-v^{\prime \prime}(1)+\varepsilon_{b, z}^{2}\left(2-\varepsilon_{p}\right)+\varepsilon_{b, z} s_{z}+\varepsilon_{b, z}^{2}\left(\varepsilon_{p}-1\right)^{2} s_{y}}
$$

Notice that, using (A.14), we can rewrite the firm $i$ 's market share and desired markup as follows:

$$
\begin{gathered}
\hat{y}_{t}(i)-\hat{Y}_{t}=\left(-\varepsilon_{p}+\varepsilon_{z} \phi_{z}\right) \tilde{p}_{t}(i) \\
\hat{\mu}_{t}(i)=\varepsilon_{\mu} \varepsilon_{p}\left(\varepsilon_{b, z} \phi_{z}-1\right) \tilde{p}_{t}(i)
\end{gathered}
$$

\section{Step 3. Deriving the New Keynesian Phillips Curve}

Equation (A.14) implies that

$$
E_{t} \tilde{z}_{t+k}(i)=\phi_{z} E_{t} \tilde{p}_{t+k}(i) \forall k>0
$$

Substituting this equality into (A.9) yields:

$$
\begin{aligned}
\Gamma \sum_{k=0}^{\infty}(\theta \beta)^{k} E_{t} \tilde{p}_{t+k}(i) & =\sum_{k=0}^{\infty}(\theta \beta)^{k} E_{t} \hat{\eta}_{t+k}+\left(\varepsilon_{p} \varepsilon_{\mu}+\left(\varepsilon_{p}-1\right) s_{y}\right) \sum_{k=0}^{\infty}(\theta \beta)^{k} \phi_{z} \varepsilon_{b, z} E_{t} \tilde{p}_{t+k}(i) \\
& \equiv \sum_{k=0}^{\infty}(\theta \beta)^{k} E_{t} \hat{\eta}_{t+k}+\varepsilon_{p}\left(\varepsilon_{\mu} \phi_{0}+s_{y} \phi_{1}\right) \sum_{k=0}^{\infty}(\theta \beta)^{k} E_{t} \tilde{p}_{t+k}(i)
\end{aligned}
$$

where the two coefficients $\phi_{0}$ and $\phi_{1}$ are respectively given by:

$$
\begin{aligned}
\phi_{0} & =\frac{\varepsilon_{b, z}^{2} \varepsilon_{\mu} \varepsilon_{p}^{2}+\varepsilon_{b, z}^{2} \varepsilon_{p} s_{y}\left(\varepsilon_{p}-1\right)}{\varepsilon_{p}^{2} \varepsilon_{\mu} \varepsilon_{b, z}^{2}-\nu^{\prime \prime}(1)+\varepsilon_{b, z}^{2}\left(2-\varepsilon_{p}\right)+\varepsilon_{b, z} s_{z}+\varepsilon_{b, z}^{2}\left(\varepsilon_{p}-1\right)^{2} s_{y}} \\
\phi_{1} & =\frac{\varepsilon_{b, z}^{2}\left(\varepsilon_{p}-1\right) \varepsilon_{\mu} \varepsilon_{p}+\varepsilon_{b, z}^{2} s_{y}\left(\varepsilon_{p}-1\right)^{2}}{\varepsilon_{p}^{2} \varepsilon_{\mu} \varepsilon_{b, z}^{2}-\nu^{\prime \prime}(1)+\varepsilon_{b, z}^{2}\left(2-\varepsilon_{p}\right)+\varepsilon_{b, z} s_{z}+\varepsilon_{b, z}^{2}\left(\varepsilon_{p}-1\right)^{2} s_{y}}
\end{aligned}
$$

Therefore, we get:

$$
\left\{1+\varepsilon_{p}\left[\left(1-\phi_{0}\right) \varepsilon_{\mu}+\left(1-\phi_{1}\right) s_{y}\right]\right\} \sum_{k=0}^{\infty}(\theta \beta)^{k} E_{t} \tilde{p}_{t+k}(i)=\sum_{k=0}^{\infty}(\theta \beta)^{k} E_{t} \hat{\eta}_{t+k}
$$

As in the canonical models, this equation relates the price chosen at time $t$ to only the future expected path of average production marginal cost. ${ }^{26}$ Therefore, by using standard manipulations, ${ }^{27}$ we finally get the following inflation equation:

$$
\hat{\pi}_{t}=\beta E_{t} \hat{\pi}_{t+1}+\zeta_{n p} \hat{\eta}_{t}
$$

\footnotetext{
${ }^{26}$ The only difference with the standard Kimball model is in fact represented by the term $\left\{1+\varepsilon_{p}\left[\left(1-\phi_{0}\right) \varepsilon_{\mu}+\left(1-\phi_{1}\right) s_{y}\right]\right\}$, since in our framework it also involves the two coefficients $\phi_{0}$ and $\phi_{1}$.

${ }^{27}$ See Galí (2008) for a formal derivation.
} 
where

$$
\zeta_{n p}=\frac{(1-\beta \theta)(1-\theta)}{\theta}\left\{\frac{1}{1+\varepsilon_{p}\left[\left(1-\phi_{0}\right) \varepsilon_{\mu}+\left(1-\phi_{1}\right) s_{y}\right]}\right\}
$$

\section{II) Proving property (i)}

Our next goal is to show that if the model economy satisfies assumptions 1-5 then

$$
\zeta_{n p}>\zeta
$$

where $\zeta$ is defined as in equation (21).

Proof: By comparing equation (21) with (23), one can easily show that this statement is equivalent of proving that for any model economy satisfying assumptions 1-5, it must be true that:

$$
0<1+\varepsilon_{p}\left[\left(1-\phi_{0}\right) \varepsilon_{\mu}+\left(1-\phi_{1}\right) s_{y}\right]<1+\varepsilon_{p}\left[\varepsilon_{\mu}+s_{y}\right]
$$

In virtue of (A.15) and (A.16), this condition depends only upon a subset of all the model structural parameters, that is the vector $\vartheta=\left[\varepsilon_{p}, \varepsilon_{b, z}, s_{z}, \varepsilon_{\mu}, s_{y}, v^{\prime \prime}(1)\right]$. Therefore, denoting with $\mathfrak{F}$ the set of all the vectors $\vartheta$ that satisfy assumption $1-5$, the statement can be proved by showing that:

$$
0<1+\varepsilon_{p}\left[\left(1-\phi_{0}\right) \varepsilon_{\mu}+\left(1-\phi_{1}\right) s_{y}\right]<1+\varepsilon_{p}\left[\varepsilon_{\mu}+s_{y}\right] \forall \vartheta \in \mathfrak{F}
$$

Our first issue is to characterize the set $\mathfrak{F}$. To this end, notice that each entry of $\vartheta$ is a long run elasticity that is obtained by evaluating the corresponding function at the non-stochastic steady-state with zero inflation. The latter is a symmetric equilibrium in which every producer charges the same price $\left(p_{t}(i)=1\right)$ and incurs in the same expenditures $\left(z_{t}(i)=1\right)$ for non-price competition; in other words such that:

$$
x_{t}(i)=1 \forall i \in[0,1]
$$

Therefore, we can explicitly characterize the set $\mathfrak{F}$ by deriving all the restrictions that assumptions $1-5$ impose on the vector of parameters $\vartheta$ by focusing only on this symmetric equilibrium with zero inflation. To this end, notice first that since $\varepsilon_{p}>1$ and assumptions $1-4$ imply both $\left[\varepsilon_{b, z}, s_{z}, \varepsilon_{\mu}, s_{y}\right] \in \mathbb{R}_{+}^{4}$ and $v^{\prime \prime}(1)$ $<0$, we must have:

$$
\mathfrak{F} \subseteq(1, \infty) \times \mathbb{R}_{+}^{4} \times(-\infty, 0)
$$

Assumption 5, in turn, imposes the existence of a unique global maximum for the profit function (12). Since the latter is twice continuously differentiable, this condition can be equivalently stated by requiring that the Hessian matrix evaluated at a maximization point is negative definite. More precisely, denoting with $\pi\left(x_{t}(i)\right)$ the firm $i$ 's profit function and with $H_{\pi}\left(x_{t}(i)\right)$ the associated Hessian matrix, that is:

$$
H_{\pi}\left(x_{t}(i)\right)=\left[\begin{array}{cc}
\frac{\partial^{2} \pi\left(x_{t}(i)\right)}{\partial^{2} Z_{t}(i)} & \frac{\partial^{2} \pi\left(x_{t}(i)\right)}{\partial Z_{t}(i) \partial p_{t}(i)} \\
\frac{\partial^{2} \pi\left(x_{t}(i)\right)}{\partial p_{t}(i) \partial Z_{t}(i)} & \frac{\partial^{2} \pi\left(x_{t}(i)\right)}{\partial^{2} p_{t}(i)}
\end{array}\right]
$$

we must have:

- both $\left.\frac{\partial^{2} \pi\left(x_{t}(i)\right)}{\partial^{2} p_{t}(i)}\right|_{x_{t}(i)=1}<0$ and $\left.\frac{\partial^{2} \pi\left(x_{t}(i)\right)}{\partial^{2} Z_{t}(i)}\right|_{x_{t}(i)=1}<0$

- $\operatorname{det}\left(H_{\pi}(1)\right)>0$

Let us start by evaluating $\partial^{2} \pi\left(x_{t}(i)\right) / \partial^{2} p_{t}(i)$. In doing this, we make use of the followings relationships:

$$
\begin{gathered}
\frac{\partial y_{t}(i)}{\partial p_{t}(i)}=-\frac{\varepsilon_{p, t}(i) y_{t}(i)}{p_{t}(i)} \\
\frac{\partial \varepsilon_{p, t}(i)}{\partial p_{t}(i)}=\varepsilon_{p, t}^{\prime}(i) \frac{b_{t}(i)}{Y_{t}} \frac{\partial y_{t}(i)}{\partial p_{t}(i)}
\end{gathered}
$$




$$
\frac{s_{y, t}(i)}{y_{t}(i)}=\left[\frac{\Phi_{y}^{\prime}\left(\frac{y_{t}(i)}{A_{t}}\right)}{A_{t} \Phi_{y}\left(\frac{y_{t}(i)}{A_{t}}\right)}\right]
$$

Therefore, by double differentiating the profit function (12) with respect to the relative price $p_{t}(i)$ we find:

$$
\frac{\partial^{2} \pi\left(x_{t}(i)\right)}{\partial^{2} p_{t}(i)}=\frac{\partial y_{t}(i)}{\partial p_{t}(i)}\left[1-\varepsilon_{p, t}(i)+\frac{s_{y, t}(i) \varepsilon_{p, t}(i)}{p_{t}(i)} \eta_{t}(i)+\frac{\eta_{t}(i)}{p_{t}(i)}\left(1+\varepsilon_{p, t}(i)\right)-\varepsilon_{p, t}^{\prime}(i) x_{t}(i)\left(1-\frac{\eta_{t}(i)}{p_{t}(i)}\right)\right]
$$

Thus, denoting with $Y_{s}$ the aggregate level of output, in the steady-state equilibrium it must be true that

$$
\begin{aligned}
\left.\frac{\partial^{2} \pi\left(x_{t}(i)\right)}{\partial^{2} p_{t}(i)}\right|_{x_{t}(i)=1} & =-\varepsilon_{p} Y_{s}\left[s_{y}\left(\varepsilon_{p}-1\right)+\frac{\varepsilon_{p}-1}{\varepsilon_{p}}-\frac{\varepsilon_{p}^{\prime}}{\varepsilon_{p}}\right] \\
& =-\varepsilon_{p} Y_{s}\left[s_{y}\left(\varepsilon_{p}-1\right)+\frac{\varepsilon_{p}-1}{\varepsilon_{p}}+\left(\varepsilon_{p}-1\right) \varepsilon_{\mu}\right]<0
\end{aligned}
$$

Given that $\varepsilon_{p}>1$ and that $Y_{s}$ is non-negative, this condition requires:

$$
\left[s_{y}\left(\varepsilon_{p}-1\right)+\frac{\varepsilon_{p}-1}{\varepsilon_{p}}+\left(\varepsilon_{p}-1\right) \varepsilon_{\mu}\right]>0
$$

However, since assumptions 2 and 4 imply that $\varepsilon_{\mu}$ and $s_{y}$ are both strictly positive, this condition is always satisfied without imposing further restrictions to the parametric space.

Let us now evaluate the term $\partial^{2} \pi\left(x_{t}(i)\right) / \partial^{2} Z_{t}(i)$. By double differentiating the profit function with respect to $Z_{t}(i)$ we obtain:

$$
\begin{aligned}
\frac{\partial^{2} \pi\left(x_{t}(i)\right)}{\partial^{2} Z_{t}(i)} & =\left(p_{t}(i)-\eta_{t}(i)\right) \frac{\partial^{2} y_{t}(i)}{\partial^{2} Z_{t}(i)}-\frac{s_{y, t}(i)}{y_{t}(i)}\left(\frac{\partial y_{t}(i)}{\partial Z_{t}(i)}\right)^{2} \eta_{t}(i)-\frac{s_{z, t}(i)}{Z_{t}(i)} \varphi_{t}(i) \\
& =\left(p_{t}(i)-\eta_{t}(i)\right)\left[\frac{\partial^{2} y_{t}(i)}{\partial^{2} Z_{t}(i)}-\frac{\partial y_{t}(i)}{\partial Z_{t}(i)} \frac{s_{z, t}(i)}{Z_{t}(i)}-\frac{s_{y, t}(i)}{y_{t}(i)}\left(\frac{\partial y_{t}(i)}{\partial Z_{t}(i)}\right)^{2}\left(\frac{\eta_{t}(i)}{p_{t}(i)-\eta_{t}(i)}\right)\right]
\end{aligned}
$$

where the last equality follows by using the optimal policy (14) in order to eliminate the term $\varphi_{t}(i)$. Using (13) we obtain:

$$
\frac{\partial y_{t}(i)}{\partial Z_{t}(i)}=\frac{y_{t}(i)}{b_{t}(i)}\left(\varepsilon_{p, t}(i)-1\right) \frac{v^{\prime}\left(z_{t}(i)\right)}{Z_{t}}
$$

and therefore, by differentiating this expression with respect to $Z_{t}(i)$, we find:

$$
\frac{\partial^{2} y_{t}(i)}{\partial^{2} Z_{t}(i)}=\frac{y_{t}(i)}{b_{t}(i)} \frac{\left(\varepsilon_{p}(i)-1\right)}{Z_{t}^{2}}\left[\left(\varepsilon_{p, t}(i)-2\right) \frac{\left(v^{\prime}\left(z_{t}(i)\right)\right)^{2}}{b_{t}(i)}+\varepsilon_{p, t}(i) \frac{\varepsilon_{p, t}^{\prime}(i)}{\left(\varepsilon_{p, t}(i)-1\right)} m_{y, t}(i)\left(v^{\prime}\left(z_{t}(i)\right)\right)^{2}+v^{\prime \prime}\left(z_{t}(i)\right)\right]
$$

Notice that in the derivation of this expression we have made use of equation (9) in order to evaluate $\partial \varepsilon_{p, t}(i) / \partial Z_{t}(i)$. Hence, denoting with $Z_{s}$ the long-run aggregate level of expenditures for non-price competition, it must be true that

$$
\begin{aligned}
\left.\frac{\partial^{2} y_{t}(i)}{\partial^{2} Z_{t}(i)}\right|_{x_{t}(i)=1} & =\frac{Y_{s}}{Z_{s}^{2}}\left(\frac{\varepsilon_{p}-1}{\varepsilon_{p}}\right)\left[\left(\varepsilon_{p}-2\right) \varepsilon_{b, z}^{2}+\varepsilon_{p} \frac{\varepsilon_{p}^{\prime}}{\left(\varepsilon_{p}-1\right)} \varepsilon_{b, z}^{2}+v^{\prime \prime}(1)-s_{z} \varepsilon_{b, z}-s_{y}\left(\varepsilon_{p}-1\right)^{2} \varepsilon_{b, z}^{2}\right] \\
& =-\frac{Y_{s}}{Z_{s}^{2}}\left(\frac{\varepsilon_{p}-1}{\varepsilon_{p}}\right)\left[\varepsilon_{p}^{2} \varepsilon_{\mu} \varepsilon_{b, z}^{2}-v^{\prime \prime}(1)+s_{z} \varepsilon_{b, z}+s_{y}\left(\varepsilon_{p}-1\right)^{2} \varepsilon_{b, z}^{2}+\left(2-\varepsilon_{p}\right) \varepsilon_{b, z}^{2}\right]<0
\end{aligned}
$$

Given that $\varepsilon_{p}>1$ and $Y_{s}$ and $Z_{s}$ are both non-negative, this condition holds if and only if:

$$
\left[\varepsilon_{p}^{2} \varepsilon_{\mu} \varepsilon_{b, z}^{2}-v^{\prime \prime}(1)+s_{z} \varepsilon_{b, z}+s_{y}\left(\varepsilon_{p}-1\right)^{2} \varepsilon_{b, z}^{2}+\left(2-\varepsilon_{p}\right) \varepsilon_{b, z}^{2}\right]>0
$$


However, the term $\left(2-\varepsilon_{p}\right) \varepsilon_{b, z}^{2}$ is negative for $\varepsilon_{p}>2$ and therefore (A.17) is not satisfied for every $\vartheta \in$ $\mathfrak{D}=(1, \infty) \times \mathbb{R}_{+}^{4} \times(-\infty, 0)$. Thus, the space of admissible vector $\vartheta$ is restricted to a set $\mathfrak{F}_{0}$ such that in the symmetric equilibrium with zero inflation condition (A.17) holds, that is:

$$
\mathfrak{F}_{0}=\left\{\vartheta \in \mathfrak{D} \mid \varepsilon_{p}^{2} \varepsilon_{\mu} \varepsilon_{b, z}^{2}-v^{\prime \prime}(1)+s_{z} \varepsilon_{b, z}+s_{y}\left(\varepsilon_{p}-1\right)^{2} \varepsilon_{b, z}^{2}+\left(2-\varepsilon_{p}\right) \varepsilon_{b, z}^{2}>0\right\}
$$

As a final issue, we have to characterize the restrictions imposed by the condition $\operatorname{det}\left(H_{\pi}(1)\right)>0$. In order to do this, we have first to determine the partial mixed derivative $\partial^{2} \pi\left(x_{t}(i)\right) / \partial p_{t}(i) \partial Z_{t}(i)$. To this end, notice first that direct differentiation of (12) implies:

$$
\frac{\partial \pi\left(x_{t}(i)\right)}{\partial p_{t}(i)}=y_{t}(i)\left(1-\varepsilon_{p, t}(i)\right)+\frac{w_{t}}{A_{t}} \Phi_{y}\left(\frac{y_{t}(i)}{A_{t}}\right) \frac{\varepsilon_{p, t}(i) y_{t}(i)}{p_{t}(i)}
$$

So differentiating this equation with respect to $Z_{t}(i)$ yields:

$$
\frac{\partial^{2} \pi\left(x_{t}(i)\right)}{\partial p_{t}(i) \partial Z_{t}(i)}=\frac{\partial y_{t}(i)}{\partial Z_{t}(i)}\left\{1-\varepsilon_{p, t}(i)\left(1-\frac{\eta_{t}(i)}{p_{t}(i)}\right)\left[1+\frac{\varepsilon_{p, t}^{\prime}(i) x_{t}(i)}{\varepsilon_{p, z}(i)-1}\right]+\frac{s_{y, t}(i) \varepsilon_{p, t}(i)}{p_{t}(i)} \eta_{t}(i)\right\}
$$

Thus

$$
\left.\frac{\partial^{2} \pi\left(x_{t}(i)\right)}{\partial p_{t}(i) \partial Z_{t}(i)}\right|_{x_{t}(i)=1}=\frac{\varepsilon_{b, z}\left(\varepsilon_{p}-1\right) Y_{s}}{Z_{s}}\left[s_{y}\left(\varepsilon_{p}-1\right)+\varepsilon_{p} \varepsilon_{\mu}\right]
$$

Therefore, in the steady-state with zero inflation the $\operatorname{det}\left(H_{\pi}(1)\right)>0$ if and only if

$$
\left[\varepsilon_{p}^{2} \varepsilon_{\mu} \varepsilon_{b, z}^{2}+s_{y}\left(\varepsilon_{p}-1\right)^{2} \varepsilon_{b, z}^{2}+\varpi\right]\left[s_{y}\left(\varepsilon_{p}-1\right)+\frac{\varepsilon_{p}-1}{\varepsilon_{p}}+\left(\varepsilon_{p}-1\right) \varepsilon_{\mu}\right]>\varepsilon_{b, z}^{2}\left(\varepsilon_{p}-1\right)\left[s_{y}\left(\varepsilon_{p}-1\right)+\varepsilon_{p} \varepsilon_{\mu}\right]^{2}
$$

where $\varpi$ is an auxiliary variable given by:

$$
\varpi=-v^{\prime \prime}(1)+s_{z} \varepsilon_{b, z}+\left(2-\varepsilon_{p}\right) \varepsilon_{b, z}^{2}
$$

With simple algebra, it is possible to show that the previous condition reduces to:

$$
1+\varepsilon_{p} \frac{\left(\varepsilon_{\mu}+s_{y}\right) \varpi+\varepsilon_{\mu} \varepsilon_{b, z}^{2} s_{y}}{\varepsilon_{p}^{2} \varepsilon_{\mu} \varepsilon_{b, z}^{2}+\varpi+\varepsilon_{b, z}^{2}\left(\varepsilon_{p}-1\right)^{2} s_{y}}>0
$$

Therefore, denoting with $\mathfrak{F}_{1}$ the set of all the vectors satisfying condition (A.18), it must be true that:

$$
\mathfrak{F}=\mathfrak{F}_{0} \cap \mathfrak{F}_{1}
$$

The set $\mathfrak{F}$ fully characterizes the space of all the vectors $\vartheta$ satisfying assumptions $1-5$. Moreover, for any vector $\vartheta \in \mathfrak{F}$ it must be also true that:

1. $\phi_{0}$ and $\phi_{1}$ are both strictly positive

2. $1+\varepsilon_{p}\left[\left(1-\phi_{0}\right) \varepsilon_{\mu}+\left(1-\phi_{1}\right) s_{y}\right]>0$

3. $\phi_{0}>\phi_{1}$

Given equations (A.15) and ((A.16), the first condition follows immediately from (A.17), while the second condition follows from (A.18) by noticing that:

$$
1+\varepsilon_{p}\left[\left(1-\phi_{0}\right) \varepsilon_{\mu}+\left(1-\phi_{1}\right) s_{y}\right]=1+\varepsilon_{p} \frac{\left(\varepsilon_{\mu}+s_{y}\right) \varpi+\varepsilon_{\mu} \varepsilon_{b, z}^{2} s_{y}}{\varepsilon_{p}^{2} \varepsilon_{\mu} \varepsilon_{b, z}^{2}+\varpi+\varepsilon_{b, z}^{2}\left(\varepsilon_{p}-1\right)^{2} s_{y}}
$$

The third condition follows by noticing that:

$$
\phi_{0}-\phi_{1}=\frac{\varepsilon_{b, z}^{2} \varepsilon_{\mu} \varepsilon_{p}+\varepsilon_{p}^{2}\left(\varepsilon_{p}-1\right) s_{y}}{\varepsilon_{p}^{2} \varepsilon_{\mu} \varepsilon_{b, z}^{2}-\nu^{\prime \prime}(1)+\varepsilon_{b, z}^{2}\left(2-\varepsilon_{p}\right)+\varepsilon_{b, z} s_{z}+\varepsilon_{b, z}^{2}\left(\varepsilon_{p}-1\right)^{2} s_{y}}>0
$$

Thus, combining together the first two conditions we find:

$$
0<1+\varepsilon_{p}\left[\left(1-\phi_{0}\right) \varepsilon_{\mu}+\left(1-\phi_{1}\right) s_{y}\right]<1+\varepsilon_{p}\left[\varepsilon_{\mu}+s_{y}\right] \forall \vartheta \in \mathfrak{F}
$$

This proves the statement. 


\section{III) Proof of property}

As final issue, we want to prove that under assumption 1-5 the slope $\zeta$ is a decreasing and bounded function of $\varepsilon_{\mu}$, converging to a strictly positive number as $\varepsilon_{\mu}$ goes to infinity.

Proof: Choose an arbitrary vector $\tau=\left[\varepsilon_{p}, \varepsilon_{b, z}, s_{z}, s_{y}, v^{\prime \prime}(1)\right] \in(1, \infty) \times \mathbb{R}_{+}^{3} \times(-\infty, 0)$ and let $\zeta_{n p}\left(\varepsilon_{\mu}\right)$ denotes the slope coefficient (23) as a function of only the elasticity $\varepsilon_{\mu}$. To ensure that assumption 1-5 are satisfied, define the set $\mathfrak{B}$ as:

$$
\mathfrak{B}=\left\{\varepsilon_{\mu} \in \mathbb{R}_{+}: \text {Conditions (A.17) and (A.18) hold } ; \tau \in(1, \infty) \times \mathbb{R}_{+}^{3} \times(-\infty, 0)\right\}
$$

so that $\varepsilon_{\mu} \in\left(\varepsilon_{\mu}^{*}, \infty\right)$, with $\varepsilon_{\mu}^{*}=\inf \mathfrak{B}$. The monotonically decreasing behavior of $\zeta_{n p}\left(\varepsilon_{\mu}\right)$ follows from (23) by noticing that direct differentiation of (A.20) yields:

$$
\frac{\partial 1+\varepsilon_{p}\left[\left(1-\psi_{0}\right) \varepsilon_{\mu}+\left(1-\psi_{1}\right) s_{y}\right]}{\partial \varepsilon_{\mu}}=\varepsilon_{p}\left[\frac{\varpi-\varepsilon_{b, z}^{2} s_{y}\left(\varepsilon_{p}-1\right)}{\varepsilon_{p}^{2} \varepsilon_{\mu} \varepsilon_{b, z}^{2}+\varpi+\varepsilon_{b, z}^{2}\left(\varepsilon_{p}-1\right)^{2} s_{y}}\right]^{2}>0 \forall \varepsilon_{\mu} \in\left(\varepsilon_{\mu}^{*}, \infty\right)
$$

This condition and (A.18) jointly imply:

$$
0<\zeta_{n p}\left(\varepsilon_{\mu}\right)<\zeta_{n p}\left(\varepsilon_{\mu}^{*}\right) \forall \varepsilon_{\mu} \in\left(\varepsilon_{\mu}^{*}, \infty\right)
$$

which in turn proves that $\zeta_{n p}\left(\varepsilon_{\mu}\right)$ is a bounded function. To show that the lower bound is strictly positive, it is enough to prove that $\zeta_{n p}\left(\varepsilon_{\mu}\right)$ converges to a positive real number as $\varepsilon_{\mu}$ goes to infinity. To this end, notice that:

$$
\begin{aligned}
\lim _{\varepsilon_{\mu} \rightarrow \infty} 1+\varepsilon_{p}\left[\left(1-\psi_{0}\right) \varepsilon_{\mu}+\left(1-\psi_{1}\right) s_{y}\right] & =1+\lim _{\varepsilon_{\mu} \rightarrow \infty} \varepsilon_{p} \frac{\left(\varepsilon_{\mu}+s_{y}\right) \varpi+\varepsilon_{\mu} \varepsilon_{b, z}^{2} s_{y}}{\varepsilon_{p}^{2} \varepsilon_{\mu} \varepsilon_{b, z}^{2}+\varpi+\varepsilon_{b, z}^{2}\left(\varepsilon_{p}-1\right)^{2} s_{y}} \\
& =1+\frac{\varpi+\varepsilon_{b, z}^{2} s_{y}}{\varepsilon_{p} \varepsilon_{b, z}^{2}} \\
& =\frac{-v^{\prime \prime}(1)+\varepsilon_{b, z}\left[s_{y} \varepsilon_{b, z}+s_{z}+2 \varepsilon_{b, z}\right]}{\varepsilon_{p} \varepsilon_{b, z}^{2}} \in \Re_{+}
\end{aligned}
$$

which, given (23), in turn implies:

$$
\lim _{\varepsilon_{\mu} \rightarrow \infty} \zeta_{n p}\left(\varepsilon_{\mu}\right)=\frac{(1-\theta \beta)(1-\theta)}{\theta}\left\{\frac{\varepsilon_{b, z}^{2} \varepsilon_{p}}{-v^{\prime \prime}(1)+\varepsilon_{b, z}\left[s_{y} \varepsilon_{b, z}+s_{z}+2 \varepsilon_{b, z}\right]}\right\}>0
$$

Therefore, we can conclude that:

$$
\zeta_{n p}>\frac{(1-\theta \beta)(1-\theta)}{\theta}\left\{\frac{\varepsilon_{b, z}^{2} \varepsilon_{p}}{-v^{\prime \prime}(1)+\varepsilon_{b, z}\left[s_{y} \varepsilon_{b, z}+s_{z}+2 \varepsilon_{b, z}\right]}\right\}>0 \forall \varepsilon_{\mu} \in\left(\varepsilon_{\mu}^{*}, \infty\right)
$$




\section{References}

[1] Calvo, Guillermo A., 1983. "Staggered prices in a utility-maximizing framework," Journal of Monetary Economics vol. 12(3), pages 383-398, September.

[2] Dixit, A. and J. Stiglitz 1977. "Monopolistic Competition and Optimum Product Diversity," American Economic Review, vol. 67(3), June, 297-308.

[3] Eichembaum, M., and Fisher, J. 2007. "Estimating the Frequency of Price Re-Optimization in Calvo Style Models," Journal of Monetary Economics, vol. 54(7), pages 2032-2047

[4] Galí, Jordi 2008. "Monetary Policy, Inflation and The Business Cycle," Princeton University Press

[5] Volker Grossmann, 2008. "Advertising, in-house R\&D, and growth," Oxford Economic Papers, vol. 60(1), pages 168-191, January.

[6] Kimball, Miles S., 1995. "The Quantitative Analytics of the Basic Neomonetarist Model," Journal of Money, Credit and Banking, vol. 27(4), pages 1241-77, November.

[7] Iwasaki, N., Kudo, Y., Tremblay, Carol H., Tremblay, Victor J., 2008: "The Advertising-price Relationship: Theory and Evidence," International Journal of the Economics of Business vol. 15(2), pages 146-167.

[8] Lambertini, Luca, and Mantovani, Andrea 2008. "Process and product innovation by a multiproduct monopolist: A dynamic approach," International Journal of Industrial Organization, forthcoming.

[9] Milgrom, Paul and Roberts, John, 1990. "Rationalizability, Learning, and Equilibrium in Games with Strategic Complementarities," Econometrica, vol. 58(6), pages 1255-77, November.

[10] Molinari, Benedetto and Turino, Francesco 2007. "Advertising, Labor Supply, and the Aggregate Economy. A Long Run Analysis," Mimeo, Universitat Pompeu Fabra

[11] Sbordone, Argia 2002. "Prices and Unit Labor Costs: A New Test of Price Stickiness," Journal of Monetary Economics vol. 49, pages 265-292

[12] Sbordone, Argia 2008. "Globalization and inflation dynamics: the impact of increased competition," Staff Reports 324, Federal Reserve Bank of New York.

[13] Spence, A Michael, 1977. "Nonprice Competition," American Economic Review, vol. 67(1), pages 255-59, February.

[14] Frank, Smets and Rafael Wouters, 2007. "Shocks and Frictions in US Business Cycles: A Bayesian DSGE Approach," American Economic Review, 97(3)) pages 586-606.

[15] Woodford, M. 2003. "Interest and Prices. Foundations of a Theory of Monetary Policy," Princeton University Press

[16] Woodford, M., 2005. "Firm-Specific Capital and the New-Keynesian Phillips Curve," International Journal of Central Banking vol. 1(2), pages 1-46 


\section{PUBLISHED ISSUES ${ }^{*}$}

WP-AD 2009-01 "Does sex education influence sexual and reproductive behaviour of women? Evidence from Mexico"

P. Ortiz. February 2009.

WP-AD 2009-02 "Expectations and frward risk premium in the Spanish power market” M.D. Furió, V. Meneu. February 2009.

WP-AD 2009-03 "Solving the incomplete markets model with aggregate uncertainty using the Krusell-Smith algorithm"

L. Maliar, S. Maliar, F. Valli. February 2009.

WP-AD 2009-04 "Employee types and endogenous organizational design: an experiment”

A. Cunyat, R. Sloof. February 2009.

WP-AD 2009-05 "Quality of life lost due to road crashes”

P. Cubí. February 2009.

WP-AD 2009-06 "The role of search frictions for output and inflation dynamics: a Bayesian assessment”

M. Menner. March 2009.

WP-AD 2009-07 "Factors affecting the schooling performance of secondary school pupils - the cost of high unemployment and imperfect financial markets"

L. Farré, C. Trentini. March 2009.

WP-AD 2009-08 “Sexual orientation and household decision making. Same-sex couples’ balance of power and labor supply choices”

S. Oreffice. March 2009.

WP-AD 2009-09 “Advertising and business cycle fluctuations”

B. Molinari, F. Turino. March 2009.

WP-AD 2009-10 "Education and selective vouchers"

A. Piolatto. March 2009.

WP-AD 2009-11 “Does increasing parents' schooling raise the schooling of the next generation? Evidence based on conditional second moments"

L. Farré, R. Klein, F. Vella. March 2009.

WP-AD 2009-12 "Equality of opportunity and optimal effort decision under uncertainty"

A. Calo-Blanco. April 2009.

WP-AD 2009-13 "Policy announcements and welfare"

V. Lepetyuk, C.A. Stoltenberg. May 2009.

WP-AD 2009-14 "Plurality versus proportional electoral rule: study of voters' representativeness" A. Piolatto. May 2009.

WP-AD 2009-15 "Matching and network effects"

M. Fafchamps, S. Goyal, M.J. van der Leij. May 2009.

WP-AD 2009-16 "Generalizing the S-Gini family -some properties-"

F.J. Goerlich, M.C. Lasso de la Vega, A.M. Urrutia. May 2009.

WP-AD 2009-17 “Non-price competition, real rigidities and inflation dynamics”

F. Turino. June 2009.

\footnotetext{
* Please contact Ivie's Publications Department to obtain a list of publications previous to 2009.
} 


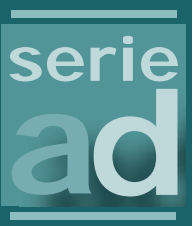

\section{I vie}

Guardia Civil, 22 - Esc. 2, 1 은

46020 Valencia - Spain

Phone: +34 963190050

Fax: +34 963190055

Department of Economics

University of Alicante

Campus San Vicente del Raspeig

03071 Alicante - Spain

Phone: +34 965903563

Fax: +34 965903898

Website: http:/ / www.ivie.es

E-mail: publicaciones@ivie.es 